\title{
Crescimento de plântulas de Pfaffia glomerata (Spreng.) Pedersen cultivadas in vitro sob dois níveis de nitrogênio e sacarose, durante seis subculturas sucessivas e aclimatização
}

\author{
Growth of Pfaffia glomerata (Spreng.) Pedersen in vitro cultured plantlets on two levels of nitrogen and \\ sucrose, during six successive subcultures and acclimatization
}

\author{
Joseila Maldaner $^{\mathrm{I}}$ Fernando Teixeira Nicoloso $^{\text {II }}$ Eneide Schutz dos Santos ${ }^{\text {III }}$ \\ Camila Kurzmann Fagundes ${ }^{\mathrm{I}}$ Rejane Flores $^{\mathrm{IV}}$ Gládis de Oliveira Jucoski $^{\mathrm{IV}}$ \\ Etiane Caldeira Skrebsky ${ }^{\text {IV }}$
}

\section{RESUMO}

O presente trabalho objetivou avaliar o crescimento de ginseng brasileiro (Pfaffia glomerata (Spreng.) Pedersen) cultivado in vitro sob dois níveis de nitrogênio e sacarose, durante seis subculturas sucessivas e aclimatização. Como fonte de explantes, utilizou-se segmentos nodais de plantas previamente estabelecidas in vitro. Foram testados dois tratamentos: $100 \%$ da concentração padrão de $\mathrm{N}$ do meio MS + $30 \mathrm{~g} L^{-1}$ sacarose; e $50 \%$ da concentração padrão de $\mathrm{N}$ do meio $M S+45 g^{-1}$ sacarose. Durante as seis subculturas sucessivas, os explantes de plantas cultivadas por 30 dias em ambos os tratamentos foram transferidos, respectivamente, para a subcultura seguinte nos mesmos tratamentos. Ao final da $6^{\underline{a}}$ subcultura, as plântulas foram transferidas para substrato Plantmax ${ }^{\circledR}$ Hortaliças e submetidas à aclimatização em sala de crescimento. Durante as subculturas, observou-se flutuações nas respostas de crescimento das plântulas às duas condições nutricionais testadas. A altura da maior brotação, a média da altura das brotações e o total de segmentos nodais por plântula, respectivamente em quatro, quatro e três subculturas, foram maiores em $100 \%$ da concentração padrão de $N$ do meio $M S$ $+30 \mathrm{~g} \mathrm{~L}^{-1}$ sacarose do que em $50 \%$ da concentração padrão de $\mathrm{N}$ do meio $\mathrm{MS}+45 \mathrm{~g} \mathrm{~L}^{-1}$ sacarose. Por outro lado, as matérias secas de raízes, da parte aérea e do total das plântulas, respectivamente em duas, duas e três subculturas, foram maiores em $100 \%$ da concentração padrão de $N$ do meio MS $+30 \mathrm{~g} \mathrm{~L}^{-1}$ sacarose. Concluiu-se que o aumento da concentração de sacarose associado à redução da concentração do $N$ estimula a produção de biomassa, enquanto o meio MS padrão estimula o crescimento em altura e número de segmentos nodais. As diferenças quanto à produção de biomassa observadas no cultivo in vitro não se refletiram no processo de aclimatização ex vitro, onde o meio MS padrão proporcionou maior crescimento em altura e número de folhas por planta.

\begin{abstract}
Palavras-chave: Ginseng brasileiro, micropropagação, produção de mudas, potencial organogênico.
\end{abstract}

\section{ABSTRACT}

The present research was aimed at evaluating the growth of brazilian ginseng (Pfaffia glomerata (Spreng.) Pedersen) in vitro cultured plantlets under two levels of nitrogen and sucrose, during six successive subcultures and acclimatization. Two nutritional treatments were tested: nitrogen at $100 \%$ strength of the MS medium $+30 \mathrm{~g} \mathrm{~L}^{-1}$ sucrose; and nitrogen at $50 \%$ strength $+45 \mathrm{~g} \mathrm{~L}^{-1}$ sucrose. During six successive subcultures, the explants of 30-day-old plantlets grown under both treatments were transferred, respectively to the next subculture on the same treatment conditions. At $6^{\text {th }}$ subculture, plantlets were transferred to substrate Plantmax ${ }^{\circledR}$ Hortaliças and submitted to acclimatization in a growth chamber. Throughout the subcultures, fluctuations in growth response due to nutritional conditions tested were observed. The height of the higher sprout, the average height of sprouts, and the total number of nodal segments per plantlet, respectively for four, four and three subcultures were greater in $100 \%$ strength of the MS medium $+30 \mathrm{~g} \mathrm{~L}^{-1}$ sucrose than in $50 \%$ strength $+45 \mathrm{~g} \mathrm{~L}^{-1}$ sucrose. On the other hand, dry matter of roots, of shoots and of the whole plant, respectively for two, two and three subcultures, were greater in $50 \%$ strength $+45 \mathrm{~g}$ $L^{-1}$ sucrose. In conclusion, the increase of sucrose associated with reduction of $N$ level in the culture medium enhanced the biomass production, while the MS at full strength enhanced the growth based in sprout length and number of nodal segments. These differences concerning the biomass production observed during in vitro culture did not persisted in the acclimatization process ex vitro, where MS at full strength give rise greater growth in sprout length and number of leaves per plant.

ICurso de Ciências Biológicas da Universidade Federal de Santa Maria (UFSM), Santa Maria, RS, Brasil.

IIDepartamento de Biologia, UFSM, Campus Universitário, Camobi, 97105-900, Santa Maria, RS, Brasil. E-mail: nicoloso@base.ufsm.br. Autor para correspondência.

IIICurso de Especialização em Ciências Biológicas, UFSM, Santa Maria, RS, Brasil.

${ }^{\text {IV }}$ Programa de Pós-graduação em Agronomia. UFSM, Santa Maria, RS, Brasil. 
Key words: Brazilian ginseng, micropropagation, seedling production, organogenic potential.

\section{INTRODUÇÃO}

A Pfaffia glomerata (Spreng.) Pedersen (família Amaranthaceae) é uma das espécies de ginseng brasileiro de grande interesse comercial devido a sua ampla utilização na indústria de fitoterápicos e fitocosméticos. Além disso, tem sido muito empregada popularmente como tônico estimulante e afrodisíaco, antitumoral e antidiabético. Em razão disso, tem ocorrido uma intensa exploração predatória das reservas naturais desta espécie, justificando a elaboração de planos de manejo ou projetos de cultivo (MONTANARI JR., 1999). Nesse sentido, atualmente várias pesquisas vêm sendo realizadas objetivando otimizar os protocolos de micropropagação para a espécie (NICOLOSO et al., 2001; RUSSOWSKI \& NICOLOSO, 2003; NICOLOSO et al., 2003; SKREBSKY et al., 2004; MALDANER et al., 2006).

As exigências nutricionais requeridas por um tecido vegetal submetido às condições in vitro variam de acordo com o genótipo (POSPÍSILOVÁ et al., 1999; HAZARIKA, 2003). Assim, o crescimento das culturas de células e tecidos vegetais in vitro depende, em parte, da otimização da concentração de nutrientes minerais, de substâncias orgânicas e fitoreguladores presentes no meio nutritivo (LEIFERT et al., 1995). O nitrogênio e a sacarose são os componentes em maior quantidade nos meio de cultura (MURASHIGE \& SKOOG, 1962), sendo que suas taxas de absorção são proporcionais à demanda gerada pelo crescimento (LEIFERT et al., 1995). Devido à baixa capacidade fotossintética das plantas cultivadas in vitro (POSPÍSILOVÁ et al., 1999; HAZARIKA, 2003), é necessária a adição de carboidratos aos meios de cultura para suprir as necessidades metabólicas, quer participando na geração de energia, quer como fonte de esqueletos carbônicos para vários processos biossintéticos implicados na diferenciação e no crescimento celulares (LEIFERT et al., 1995). A sacarose é o carboidrato mais apropriado para a multiplicação in vitro da P. glomerata (NICOLOSO et al., 2003).

Durante o cultivo in vitro, os explantes, os órgãos e as plantas inteiras crescem sob condições ambientais especiais, que resultam na formação de plântulas com características morfológicas, anatômicas e fisiológicas anormais. Entretanto, essas podem ser revertidas após a transferência para cultivo ex vitro (POSPÌSILOVÀ et al., 1999; KADLECEK et al., 2001). Em função disso, a aclimatização é um processo que, para ser bem sucedido, deve acontecer gradualmente (HAZARIKA, 2003). O aumento, a eliminação e/ou a redução da concentração de carboidratos no meio de cultura pode ser determinante no sucesso da aclimatização (SOLAROVA et al., 1989; LEIFERT et al., 1995; POSPÍSILOVÁ et al., 1999; HAZARIKA, 2003; SKREBSKY et al., 2004).

A influência da concentração de sacarose do meio de cultura que precede o período de aclimatização vem sendo avaliada em muitas espécies (POSPÍSILOVÁ et al., 1999; KADLECEK et al., 2001; SEELYE et al., 2003; HAZARIKA, 2003; FUENTES et al., 2005). Plantas de côco (Cocos nucifera L.) apresentaram crescimento lento quando transferidas para a condição ex vitro, devido a uma limitada capacidade fotossintética no cultivo in vitro, aparentemente causada pela adição de sacarose no meio de cultura, provocando feedback negativo para a fotossíntese (FUENTES et al., 2005). Para mudas de $\boldsymbol{P}$. glomerata, SKREBSKY et al. (2004) constataram incremento significativo na matéria seca das plantas durante a aclimatização ex vitro e o cultivo a campo através do aumento isolado da concentração de sacarose no meio MS; porém, esses autores testaram essa variação apenas como fator de pré-tratamento, ou seja, na subcultura in vitro que antecedeu a aclimatização.

Estudos evidenciam que doses elevadas de sacarose afetam consideravelmente o desempenho fotossintético de plantas transferidas para cultivo ex vitro (SOLAROVA et al., 1989; POSPÍSILOVÁ et al., 1999; HAZARIKA, 2003), ao passo que a ausência desse carboidrato é citada como causa de elevadas taxas de mortalidade das plantas nesta condição (SEELYE et al., 2003; FUENTES et al., 2005).

A multiplicação in vitro de $\boldsymbol{P}$. glomerata sob condições de redução em $50 \%$ da concentração de nitrogênio do meio MS e o aumento da dose usual de sacarose para $45 \mathrm{~g} \mathrm{~L}^{-1}$, apenas por uma subcultura, favoreceu o crescimento em altura de brotações, o número de segmentos nodais e de brotações, bem como a produção de biomassa das plântulas, devido ao estímulo ao uso de carbono (MALDANER et al., 2006).

O número de subculturas também tem sido relatado como um dos fatores influentes no sucesso do enraizamento in vitro, sendo que, em geral, a formação de raízes declina com as subculturas sucessivas (PIERIK, 1990). Por outro lado, em Malus domestica var. Joanathan, verificou-se que um número crescente de subculturas promoveu o aumento na porcentagem de enraizamento (SÁNCHEZ et al., 1997). Para o cultivo de castanha (Castanea sativa Mill.), esses mesmos autores encontraram uma tendência de 
aumento da porcentagem de enraizamento nas primeiras subculturas jovens (da $1^{\text {a }}$ até a $6^{\text {a }}$ ), mas não reportaram se esta tendência continua com subculturas posteriores ou se isso se inverte.

Tendo em vista a otimização da micropropagação da $\boldsymbol{P}$. glomerata, o presente trabalho objetivou avaliar o crescimento das plântulas multiplicadas in vitro sob dois níveis de nitrogênio e sacarose, durante seis subculturas sucessivas e na sua posterior aclimatização.

\section{MATERIAL E MÉTODOS}

O experimento foi desenvolvido no Laboratório de Biotecnologia Vegetal do Departamento de Biologia da Universidade Federal de Santa Maria (UFSM).

Como fonte de explantes para a $1^{\mathrm{a}}$ subcultura, foram utilizados segmentos nodais $(1,0 \mathrm{~cm}$ de comprimento e sem folhas) de plantas de Pfaffia glomerata cultivadas in vitro em meio de cultura MS (MURASHIGE \& SKOOG, 1962) acrescido de 30 $\mathrm{g} \mathrm{L}^{-1}$ de sacarose, $100 \mathrm{mg} \mathrm{L}^{-1}$ de mio-inositol e $6 g \mathrm{~L}^{-1}$ de ágar, conforme metodologia descrita por NICOLOSO et al. (2001).

Foram testados dois tratamentos: Tratamento controle: $100 \%$ da concentração padrão de $\mathrm{N}$ do meio $\mathrm{MS}+30 \mathrm{~g} \mathrm{~L}^{-1}$ sacarose; e Tratamento alternativo: $50 \%$ da concentração padrão de $\mathrm{N}$ do meio $\mathrm{MS}+45 \mathrm{~g} \mathrm{~L}^{-1}$ sacarose. Esses tratamentos foram testados no decorrer de seis subculturas sucessivas, nos quais os explantes utilizados originaram-se de plantas submetidas ao mesmo tratamento. As subculturas foram feitas a cada 30 dias. $\mathrm{O}$ pH do meio de cultura foi ajustado para 5,8 antes da inclusão do ágar e da autoclavagem (1atm, $120^{\circ} \mathrm{C}, 15$ minutos). Após a inoculação, os explantes foram cultivados em sala de crescimento com temperatura de $25 \pm 2^{\circ} \mathrm{C}$, fotoperíodo de $16 \mathrm{~h}$ e intensidade luminosa de $35 \mathrm{mmol}$ $\mathrm{m}^{-2} \mathrm{~s}^{-1}$ fornecida por lâmpadas fluorescentes brancasfrias.

As avaliações de crescimento foram realizadas ao final de cada subcultura através da altura média das brotações, da altura da maior brotação, do número médio de segmentos nodais, da matéria seca de raízes, da parte aérea e do total das plantas, bem como da relação entre matéria seca de raízes e parte aérea. O número médio de raízes por plântula foi avaliado do 7ํa ao 15 dia após a inoculação dos explantes.

Plântulas completas, com 25 dias de idade e pertencentes à 6a subcultura, foram submetidas a aclimatização, conforme a metodologia parcialmente modificada e descrita para a $\boldsymbol{P}$. glomerata por
SKREBSKY et al. (2004). Resumidamente, após o cultivo in vitro e a abertura dos tubos de cultivo em sala de crescimento, por período de três dias, fez-se a transferência das plântulas para recipientes plásticos $\left(350 \mathrm{~cm}^{3}\right)$ contendo $250 \mathrm{~cm}^{3}$ de Plantmax ${ }^{\circledR}$ Hortaliças. Nessa etapa, as plantas permaneceram por 30 dias em sala de crescimento, sob as mesmas condições ambientais utilizadas para o cultivo in vitro, com exceção da umidade relativa do ar, a qual foi de $60-70 \%$. Aos 5, 10, 15 e 30 dias após a transferência, as plantas foram avaliadas quanto à altura média das brotações, à altura da maior brotação e ao número de folhas por planta. A matéria seca de raízes, da parte aérea e do total da planta, bem como a relação entre matéria seca de raízes e parte aérea, foram avaliadas somente aos 30 dias.

O delineamento experimental foi o inteiramente ao acaso com 30 repetições, exceto na $6^{\text {a }}$ subcultura, em que foram utilizadas 60 repetições por tratamento. A parcela experimental consistiu de um tubo de ensaio (25mm de diâmetro, $150 \mathrm{~mm}$ de altura) contendo $10 \mathrm{~mL}$ de meio de cultura MS, modificado nas concentrações de nitrogênio e sacarose, segundo os tratamentos definidos acima, e um segmento nodal. Os dados experimentais foram submetidos à análise de variância. O comportamento individual dos parâmetros de crescimento das plantas foi avaliado por regressões polinomiais para o fator épocas de avaliação e comparação de médias (Teste Tukey) para o fator tratamentos nutricionais, a 5\% de probabilidade de erro. Utilizou-se o software científico - NTIA, desenvolvido pelo Centro Nacional de Pesquisa Tecnológica em Informática para Agricultura (EMBRAPA, 1997).

\section{RESULTADOS E DISCUSSÃO}

O enraizamento das plântulas foi crescente em ambos os tratamentos a partir do 7oㅡ ou 8o dia após a inoculação (DAI) dos explantes. O desempenho em número de raízes por plântula alternou-se ao longo das seis subculturas para os dois tratamentos, sendo maior no tratamento controle (Tc) na 3ㄹ $5^{\underline{a}}$ e $6^{\underline{a}}$ subculturas (Figuras 1C, 1E, 1F), e, para o tratamento alternativo

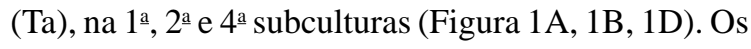
níveis de sacarose e nutrientes minerais dos meios de cultura influenciam vários processos metabólicos, os quais apresentam efeito sobre o crescimento e diferenciação dos tecidos. O aumento da concentração de sacarose foi benéfico na formação de raízes de algumas espécies (GEORGE, 1996). Por outro lado, a redução na concentração de sacarose melhorou o enraizamento de batata (ANDRADE, 1998). Segundo LEIFERT et al. (1995), a redução da concentração de N 


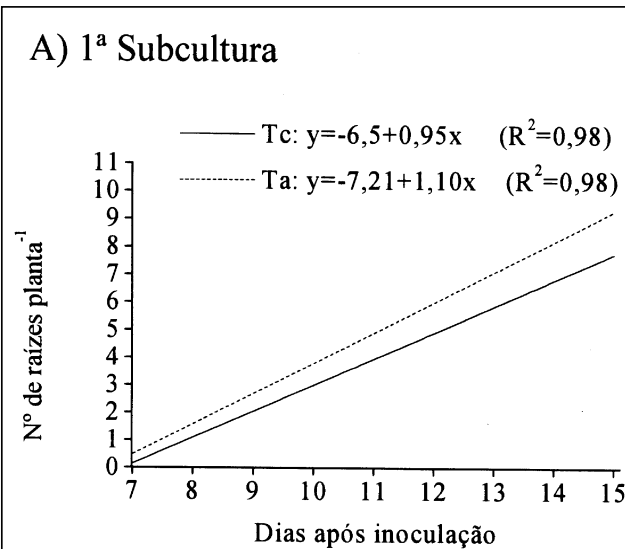

C) $3^{\text {a }}$ Subcultura

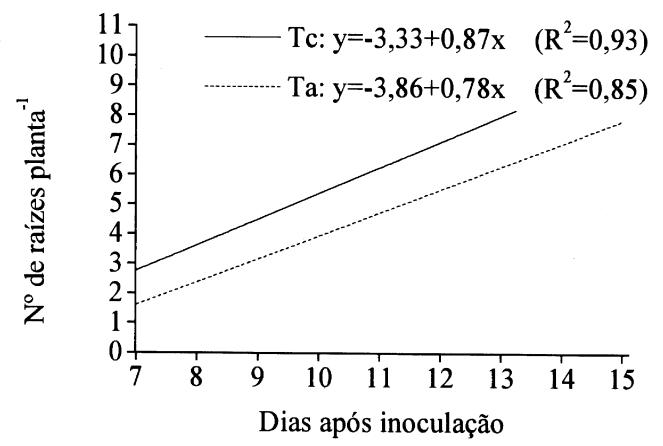

E) $5^{\mathrm{a}}$ Subcultura

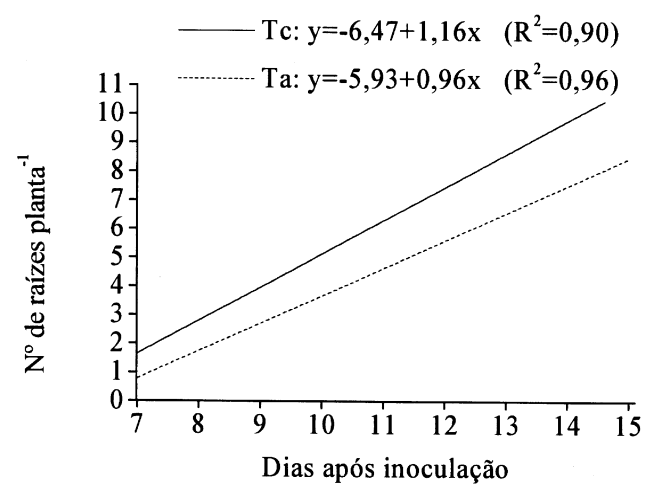

B) $2^{\text {a }}$ Subcultura

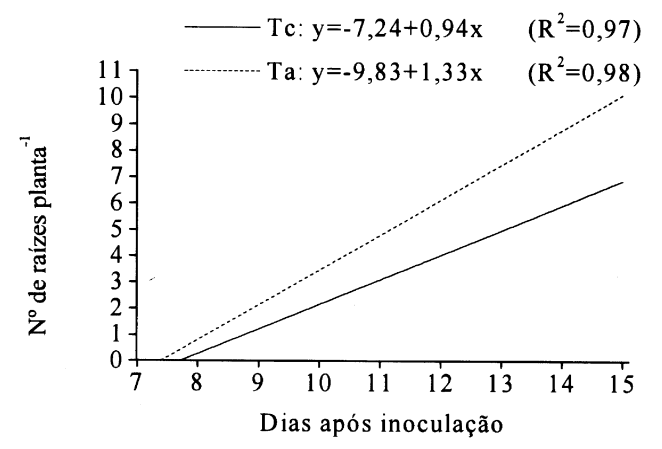

D) $4^{\text {a }}$ Subcultura

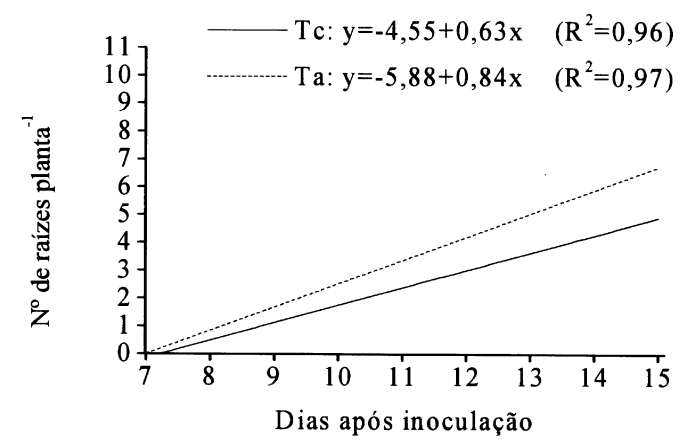

F) $6^{\mathrm{a}}$ Subcultura

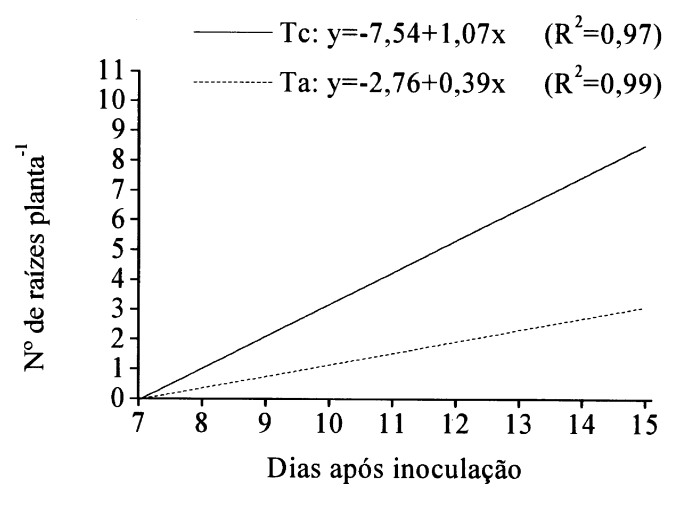

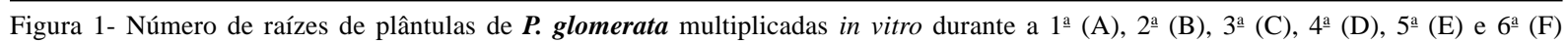
subculturas sob dois regimes nutricionais: Tc (Tratamento controle): $100 \%$ de $\mathrm{N}$ do meio $\mathrm{MS}+30 \mathrm{~g} \mathrm{~L}^{-1}$ sacarose; e Ta (Tratamento alternativo): $50 \%$ de $\mathrm{N}$ do meio $\mathrm{MS}+45 \mathrm{~g} \mathrm{~L}^{-1}$ sacarose.

pela metade da concentração do meio MS é um procedimento muito comum na indução de enraizamento. De fato, RUSSOWSKI \& NICOLOSO (2003), testando a variação isolada de doses de N e P do meio de cultura MS, observaram que o número de raízes de $\boldsymbol{P}$. glomerata multiplicada in vitro foi maior utilizando-se $50 \%$ de N. Por outro lado, NICOLOSO et al. (2001) não constataram influência da variação

Ciência Rural, v.37, n.1, jan-fev, 2007. 
conjunta dos macronutrientes do meio MS no número de raízes de plantas de $\boldsymbol{P}$. glomerata produzidas in vitro.

Os explantes apresentaram alta capacidade organogênica para ambos os tratamentos, uma vez que plantas completas e bem desenvolvidas foram obtidas em menos de 30 dias de cultivo. Entretanto, constatouse que as alterações das concentrações de nitrogênio e sacarose utilizadas afetaram significativamente o crescimento das plantas. $\mathrm{O}$ crescimento das brotações e o número de segmentos nodais por plântula foram, respectivamente, em quatro e três subculturas, maiores no Tc (Tabela 1). De modo similar, RUSSOWSKI \& NICOLOSO (2003) reportaram que a concentração padrão de $\mathrm{N}$ do meio MS proporcionou maior altura de brotações de $\boldsymbol{P}$. glomerata multiplicada in vitro. Já SKREBSKY et al. (2004), ao testarem o efeito isolado de doses de sacarose do meio de cultura, observaram que a altura de brotações de $\boldsymbol{P}$. glomerata apresentou dose de máxima eficiência técnica estimada à sacarose de 30 a $45 \mathrm{~g} \mathrm{~L}^{-1}$ aos 10 DAI, e aos 25 e 32 DAI, entre 45 e $60 \mathrm{~g} \mathrm{~L}^{-1}$. Em samambaia-espada (Nephrolepsis exaltata), GUIMARÃES et al. (1999) registraram que o maior comprimento de brotos ocorreu na ausência de sacarose e a $25 \%$ de N. Esses resultados demonstram que as respostas à interação entre doses de $\mathrm{N}$ e Creduzido no meio de cultura variam em função da espécie vegetal em questão.

Os resultados obtidos demonstram que houve um declínio no número de segmentos nodais por planta para ambos os tratamentos testados, sendo marcante na $6^{\text {a }}$ subcultura para o Tc e a partir da $4^{\text {a }}$ subcultura para o Ta (Tabela 1). Este parâmetro de crescimento é importante porque reflete a taxa de multiplicação, a qual está diretamente relacionada com

Tabela 1 - Parâmetros de crescimento de plântulas de $\boldsymbol{P}$. glomerata multiplicadas in vitro durante seis subculturas sucessivas sob dois regimes nutricionais: Tc (Tratamento controle): $100 \%$ de $\mathrm{N}$ do meio $\mathrm{MS}+30 \mathrm{~g} \mathrm{~L}^{-1}$ sacarose; e Ta (Tratamento alternativo): $50 \%$ de $\mathrm{N}$ do meio $\mathrm{MS}+45 \mathrm{~g} \mathrm{~L}^{-1}$ sacarose.

\begin{tabular}{|c|c|c|c|c|c|c|}
\hline \multirow{2}{*}{ Tratamentos nutricionais } & \multicolumn{6}{|c|}{ Subculturas in vitro } \\
\hline & $1^{a}$ & $2^{a}$ & $3^{a}$ & $4^{a}$ & $5^{\mathrm{a}}$ & $6^{a}$ \\
\hline & \multicolumn{6}{|c|}{ Média de altura das brotações (cm) } \\
\hline Tc: $100 \%$ de $\mathrm{N}$ e $30 \mathrm{~g} \mathrm{~L}^{-1}$ sacarose & $3,09 a^{*}$ & $2,40 \mathrm{~b}$ & 3,95 a & 3,92 a & 4,09 a & $2,48 \mathrm{a}$ \\
\hline \multirow[t]{2}{*}{ Ta: $50 \%$ de $\mathrm{N}$ e $45 \mathrm{~g} \mathrm{~L}^{-1}$ sacarose } & $2,27 \mathrm{~b}$ & 4,09 a & $3,54 \mathrm{a}$ & $1,64 \mathrm{~b}$ & $0,92 \mathrm{~b}$ & $0,42 \mathrm{~b}$ \\
\hline & \multicolumn{6}{|c|}{ Altura média da maior brotação (cm) } \\
\hline Tc: $100 \%$ de $\mathrm{N}$ e $30 \mathrm{~g} \mathrm{~L}^{-1}$ sacarose & 4,8 a & $4,1 \mathrm{~b}$ & 6,8 a & $6,7 \mathrm{a}$ & 6,2 a & $4,27 \mathrm{a}$ \\
\hline \multirow[t]{2}{*}{ Ta: $50 \%$ de $\mathrm{N}$ e $45 \mathrm{~g} \mathrm{~L}^{-1}$ sacarose } & $3,4 \mathrm{~b}$ & $6,2 \mathrm{a}$ & 6,1 a & $2,7 \mathrm{~b}$ & $1,7 \mathrm{~b}$ & $0,82 \mathrm{~b}$ \\
\hline & \multicolumn{6}{|c|}{ Número médio de segmentos nodais planta ${ }^{-1}$} \\
\hline Tc: $100 \%$ de $\mathrm{N}$ e $30 \mathrm{~g} \mathrm{~L}^{-1}$ sacarose & 5,0 a & $4,5 \mathrm{~b}$ & 5,5 a & $5,1 \mathrm{a}$ & $5,8 \mathrm{a}$ & $3,86 \mathrm{a}$ \\
\hline \multirow[t]{2}{*}{ Ta: $50 \%$ de $\mathrm{N}$ e $45 \mathrm{~g} \mathrm{~L}^{-1}$ sacarose } & 4,4 a & 5,7 a & 5,1 a & $3,4 \mathrm{~b}$ & $2,5 \mathrm{~b}$ & $1,77 \mathrm{~b}$ \\
\hline & \multicolumn{6}{|c|}{ Matéria seca total das plantas (mg planta ${ }^{-1}$ ) } \\
\hline Tc: $100 \%$ de $\mathrm{N}$ e $30 \mathrm{~g} \mathrm{~L}^{-1}$ sacarose & 41,5 a & $27,8 \mathrm{~b}$ & $34,8 \mathrm{~b}$ & $44,9 \mathrm{~b}$ & 59,2 a & 39,5 a \\
\hline \multirow[t]{2}{*}{ Ta: $50 \%$ de $\mathrm{N}$ e $45 \mathrm{~g} \mathrm{~L}^{-1}$ sacarose } & 49,7 a & 58,8 a & 57,4 a & 81,9 a & 62,7 a & $19,7 \mathrm{~b}$ \\
\hline & \multicolumn{6}{|c|}{ Matéria seca das raízes (mg planta ${ }^{-1}$ ) } \\
\hline Tc: $100 \%$ de $\mathrm{N}$ e $30 \mathrm{~g} \mathrm{~L}^{-1}$ sacarose & $15,7 \mathrm{~b}$ & $14,1 \mathrm{~b}$ & $16,0 \mathrm{a}$ & 28,6 a & 40,3 a & 22,7 a \\
\hline \multirow[t]{2}{*}{ Ta: $50 \%$ de $\mathrm{N}$ e $45 \mathrm{~g} \mathrm{~L}^{-1}$ sacarose } & 24,6 a & 32,0 a & 36,9 a & $43,4 \mathrm{a}$ & 44,9 a & $11,1 \mathrm{~b}$ \\
\hline & \multicolumn{6}{|c|}{ Matéria seca da parte aérea (mg planta ${ }^{-1}$ ) } \\
\hline Tc: $100 \%$ de $\mathrm{N}$ e $30 \mathrm{~g} \mathrm{~L}^{-1}$ sacarose & 25,7 a & $13,7 \mathrm{~b}$ & $18,7 \mathrm{a}$ & $16,3 \mathrm{~b}$ & $18,8 \mathrm{a}$ & $16,8 \mathrm{a}$ \\
\hline \multirow[t]{2}{*}{ Ta: $50 \%$ de $\mathrm{N}$ e $45 \mathrm{~g} \mathrm{~L}^{-1}$ sacarose } & 25,1 a & 26,8 a & 20,4 a & 38,5 a & $17,8 \mathrm{a}$ & 8,5 a \\
\hline & \multicolumn{6}{|c|}{ Relação entre matéria seca de raízes e parte aérea } \\
\hline Tc: $100 \%$ de $\mathrm{N}$ e $30 \mathrm{~g} \mathrm{~L}^{-1}$ sacarose & $0,71 \mathrm{a}$ & $1,1 \mathrm{a}$ & $0,91 \mathrm{a}$ & 1,76 a & $2,80 \mathrm{a}$ & $1,35 \mathrm{a}$ \\
\hline Ta: $50 \%$ de $\mathrm{N}$ e $45 \mathrm{~g} \mathrm{~L}^{-1}$ sacarose & 0,95 a & $1,6 \mathrm{a}$ & 1,49 a & $1,24 \mathrm{a}$ & 3,67 a & $0,43 \mathrm{a}$ \\
\hline
\end{tabular}

* Médias seguidas da mesma letra, na coluna, não diferem entre si pelo teste de Tukey a 5\% de probabilidade de erro. 
a eficiência do processo de propagação via gemas axilares. De acordo com MANTELL et al. (1994), em algumas espécies, verifica-se uma redução na organogênese ao longo das subculturas. Adicionalmente, um elevado número de subculturas também está relacionado com a regeneração de plantas com alterações genéticas e/ou epigenéticas (KLERK, 1990), o que compromete seriamente a propagação clonal. Dessa forma, o presente trabalho evidencia que a redução da concentração de N e o aumento da concentração de sacarose no meio de cultura MS não é adequada para o processo de multiplicação in vitro da $P$. glomerata.

Quanto à biomassa, verificou-se um incremento na matéria seca total das plantas pelo tratamento com a concentração de $\mathrm{N}$ reduzida a 50\% e com adição de $45 \mathrm{~g} \mathrm{~L}^{-1}$ de sacarose na $2^{\underline{a}}$, $3^{\text {a }}$ e $4^{\mathrm{a}}$ subculturas (Tabela 1). Esse tratamento alternativo proporcionou menor produção de biomassa apenas na $6^{\mathfrak{a}}$ subcultura, provavelmente em função da acentuação do declínio do crescimento das plantas a partir da $4^{\text {a }}$ subcultura (Tabela 1). O aumento da biomassa de $\boldsymbol{P}$. glomerata multiplicada in vitro através do aumento da concentração de sacarose no meio de cultura também foi registrado por NICOLOSO et al. (2003), SKREBSKY et al. (2004) e MALDANER et al. (2006).

As alterações na concentração $\mathrm{N}$ e sacarose não afetaram significativamente a relação entre matéria seca de raízes e parte aérea (Tabela 1). Este parâmetro, dentre outros, parece ser importante no processo de aclimatização das plantas, em função de a partição de biomassa entre sistema radicular e parte aérea afetar o pegamento das mudas quando transferidas ao campo.

Durante o processo de aclimatização, a altura de plantas, o número de brotações e o número de folhas por planta foi maior para aquelas produzidas sob efeito do Tc. De modo semelhante, FUENTES et al. (2005) demonstraram que plantas de côco (Cocos nucifera L.) apresentaram crescimento lento na aclimatização quando foram cultivadas em meio de cultura suplementado com elevadas concentrações de sacarose. Apesar de não ter ocorrido efeito dos tratamentos testados na relação entre a matéria seca de raízes e parte aérea (Tabela 2), durante a aclimatização, constatou-se que a redução da concentração de $\mathrm{N}$ e o aumento da sacarose não foram benéficos para a altura de plantas e número de folhas (Figura 2A, 2B e 2C), fato que culminou na redução da biomassa da parte aérea (Tabela 2). Apesar disso, durante a aclimatização, não houve diferença entre os tratamentos no que diz respeito à matéria seca total das plantas e de raízes (Tabela 2). Para a mesma espécie, SKREBSKY et al. (2004) constataram aumento significativo na matéria seca das plantas durante a aclimatização ex vitro e o cultivo a campo através do aumento isolado da concentração de sacarose no meio MS. Entretanto, esses autores testaram essa variação nutricional apenas como fator de pré-tratamento, ou seja, na subcultura in vitro que antecedeu a aclimatização.

Estes resultados, juntamente àqueles publicados por NICOLOSO et al. (2001), NICOLOSO et al. (2003), SKREBSKY et al. (2004) e MALDANER et al. (2006), mostram que as alterações na composição do meio de cultura devem levar em conta o objetivo a ser alcançado, sendo que, para a fase de multiplicação in vitro da $\boldsymbol{P}$. glomerata, o meio MS padrão é o mais adequado. Por outro lado, recomenda-se como prétratamento o aumento da concentração de sacarose associada à redução da concentração de $\mathrm{N}$ para a produção de mudas aclimatizadas.

\section{CONCLUSÃO}

Durante seis subculturas sucessivas, a concentração padrão de $\mathrm{N}$ do meio $\mathrm{MS}$, associada a $30 \mathrm{~g} \mathrm{~L}^{-1}$ de sacarose, favoreceu o crescimento e a multiplicação in vitro de $\boldsymbol{P}$. glomerata, enquanto a redução da concentração de $\mathrm{N}$, em conjunto com o aumento da de sacarose para $45 \mathrm{~g} \mathrm{~L}^{-1}$, aumentou a produção de biomassa. O potencial organogênico dos explantes diminuiu nas sucessivas subculturas. Plantas produzidas in vitro em sucessivas subculturas no meio de cultura MS padrão tiveram maior crescimento durante a aclimatização.

Tabela 2 - Biomassa de $\boldsymbol{P}$. glomerata aos 30 dias de aclimatização ex vitro de plantas originadas da cultura in vitro sob dois regimes nutricionais: Tc (Tratamento controle): $100 \%$ da concentração padrão de $\mathrm{N}$ do meio $\mathrm{MS}+30 \mathrm{~g} \mathrm{~L}^{-1}$ sacarose; e Ta (Tratamento alternativo): $50 \%$ da concentração padrão de $\mathrm{N}$ do meio $\mathrm{MS}+45 \mathrm{~g} \mathrm{~L}^{-1}$ sacarose.

\begin{tabular}{|c|c|c|c|c|}
\hline \multirow{2}{*}{$\begin{array}{l}\text { Tratamentos nutricionais usados no cultivo } \\
\text { in vitro }\end{array}$} & \multicolumn{4}{|c|}{ matéria seca (mg planta ${ }^{-1}$ ) } \\
\hline & Total da planta & Parte aérea & Raízes & Relação matéria seca de raízes/parte aérea \\
\hline Tc: $100 \%$ de $\mathrm{N}$ e $30 \mathrm{~g} \mathrm{~L}^{-1}$ sacarose & $55,6 a^{*}$ & 46,0 a & 9,5 a & $0,17 \mathrm{a}$ \\
\hline Ta: $50 \%$ de $\mathrm{N}$ e $45 \mathrm{~g} \mathrm{~L}^{-1}$ sacarose & 37,9 a & $31,0 \mathrm{~b}$ & $6,8 \mathrm{a}$ & $0,21 \mathrm{a}$ \\
\hline
\end{tabular}

* Médias seguidas da mesma letra, na coluna, não diferem entre si pelo teste de Tukey a 5\% de probabilidade de erro. 
A)

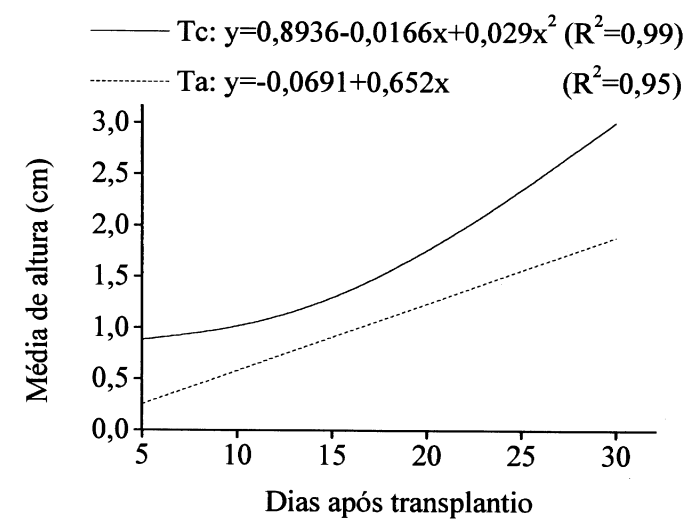

B)

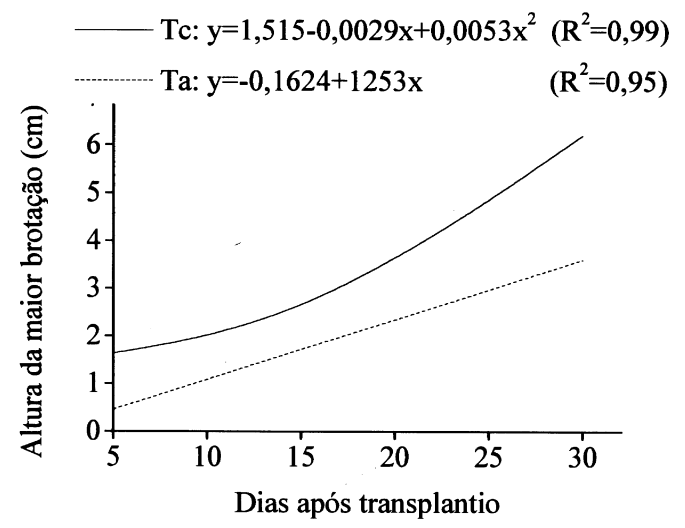

C)

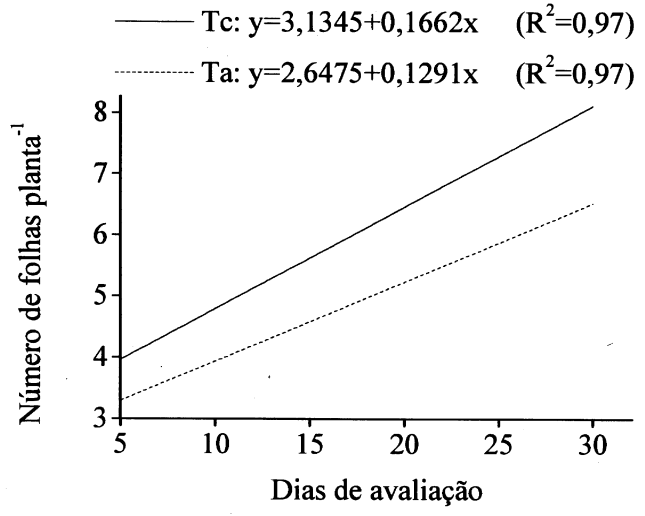

Figura 2 - Altura média das brotações (A), altura da maior brotação (B) e número de folhas por plântula (C) durante a aclimatização ex vitro de plantas de $\boldsymbol{P}$. glomerata originadas da cultura in vitro sob dois regimes nutricionais: Tc (tratamento controle): $100 \%$ da concentração de $\mathrm{N}$ do meio $\mathrm{MS}+30 \mathrm{~g} \mathrm{~L}^{-1}$ sacarose; e Ta (tratamento alternativo): $50 \%$ da concentração de $\mathrm{N}+45 \mathrm{~g} \mathrm{~L}^{-1}$ sacarose.

\section{AGRADECIMENTOS}

À Fundação de Amparo à Pesquisa do Estado do Rio Grande do Sul (FAPERGS), ao Conselho de Aperfeiçoamento de Pessoal e Ensino Superior (CAPES) e ao Conselho Nacional de Desenvolvimento Científico e Tecnológico (CNPq), pelo apoio financeiro concedido.

\section{REFERÊNCIAS}

ANDRADE, L.B. Efeito do meio de cultura, tipos de explante e períodos de escuro sobre a micropropagação da batata (Solanum tuberosum L.), cv. Cristal. 1998. 60f. Dissertação (Mestrado em Agronomia) - Curso de Pós-graduação em Agronomia, Universidade Federal de Pelotas.

EMBRAPA. Ambiente de software NTIA, versão 4.2.2 manual usuário. Campinas: Centro Nacional de Pesquisa Tecnológica em Informática para a Agricultura, 1997. 258p.
FUENTES, G. et al. Exogenous sucrose can decrease in vitro photosynthesis but improve field survival and growth of coconut (Cocos nucifera L.) in vitro plantlets. In Vitro Cellular and Developmental Biology - Plant, v.41, n.1, p.69-76, 2005.

GEORGE, E.F. Plant propagation by tissue culture. Edington: Exegetics, 1996. Part 2, 1361p.

GUIMARÃES, P.T.C. et al. Efeito de diferentes concentrações de nitrogênio e de sacarose sobre a propagação in vitro da samambaia-espada [Nephrolepis exaltata (L.) Schott]. Ciência e Agrotecnologia, Lavras, v.23, n.2, p.309-316, 1999.

HAZARIKA, B.N. Acclimatization of tissue-cultured plants. Current Science, Stamford, v.85, n.12, p.1704-1712, 2003.

KADLECEK, P. et al. Importance of in vitro pretreatment for ex vitro acclimatization and growth. Plant Science, Limerick, v.161, p.695-701, 2001. 
KLERK, G.J. How to measure somaclonal variation. Acta Botanica Neerlandica, Oxford, v.38, n.2, p.129-144, 1990.

LEIFERT, C. et al. Mineral and carbohydrate nutrition of plant cell and tissue cultures. Critical Reviews in Plant Sciences, Boca Raton, v.14, n.2, p.83-109, 1995.

MALDANER, J. et al. Sacarose e nitrogênio na multiplicação in vitro de Pfaffia glomerata (Spreng.) Pedersen. Ciência Rural, Santa Maria, v.36, n.4, p.1201-1206, 2006.

MANTELL, S.H. et al. Princípios de biotecnologia em plantas: uma introdução à engenharia genética em plantas. Ribeirão Preto: Sociedade Brasileira de Genética, 1994. 333p.

MONTANARI JR., I. Aspectos do cultivo comercial do ginseng brasileiro (Pfaffia glomerata (Spreng) Pedersen). São Paulo: CPQBA-UNICAMP, 1999. 3p. (Boletim Agroecológico, 12).

MURASHIGE, T.; SKOOG, F. A revised medium for rapid growth and bioassays with tobacco tissue cultures. Physiologia Plantarum, Copenhagen, v.15, p.473-497, 1962.

NICOLOSO, F.T. et al. Micropropagação do ginseng brasileiro [Pfaffia glomerata (Spreng.) Pedersen]. Revista Brasileira de Plantas Medicinais, Botucatu, v.3, n.2, p.11-18, 2001.

NICOLOSO, F.T. et al. Efeito de concentrações e fontes de carboidratos no crescimento de plantas de ginseng brasileiro
(Pfaffia glomerata (Spreng.) Pedersen) cultivadas in vitro. Ciência e Agrotecnologia, Lavras, v.27, n.1, p.84-90, 2003.

PIERIK, R. Cultivo in vitro de las plantas superiores. Madrid: Mundi-Prensa, 1990. 326p.

POSPÍSILOVÁ, J. et al. Acclimatization of micropropagated plants to ex vitro conditions. Biologia Plantarum, Netherlands, v.42, n.4, p. 481-497, 1999.

RUSSOWSKI, D.; NICOLOSO, F.T. Nitrogênio e fósforo no crescimento de plantas de Ginseng Brasileiro [Pfaffia glomerata (Spreng.) Pedersen] cultivadas in vitro. Ciência Rural, Santa Maria, v.33, n.1, p.57-63, 2003.

SÁNCHEZ, M.C. et al. Reinvigoration treatments for the micropropagation of mature chestnut trees. Annual Science Forum, Espanha, v.54, p.359-370, 1997.

SEELYE, J.F. et al. Acclimatizing tissue culture plants: reducing the shock. Combined Proceedings International Plant Propagators' Society, Nova Zelandia, v.53, p.85-90, 2003.

SKREBSKY, E.C. et al. Sacarose e período de cultivo in vitro na aclimatização ex vitro de ginseng brasileiro (Pfaffia glomerata Spreng. Pedersen). Ciência Rural, Santa Maria, v.34, n.5, p.1471-1477, 2004.

SOLAROVA, J. et al. Photosynthesis and growth of tobacco plants in dependence on carbon supply. Photosynthetica, Dordrecht, v.23, p.629-637, 1989. 